\title{
Possible Pathway for Ifosfamide Degradation via Fe-TiO Assisted Photo Catalysis
}

\begin{abstract}
LUCIAN ALEXANDRU CONSTANTIN ${ }^{1 *}$, MIRELA ALINA CONSTANTIN ${ }^{1}$, INES NITOI ${ }^{1}$, FLORENTINA LAURA CHIRIAC ${ }^{1}$, TOMA GALAO N ${ }^{1}$, NICOLAE IONUT CRISTEA ${ }^{1,2}$

${ }^{1}$ National Research and Development Institute for Industrial Ecology - ECOIND Bucharest, 71-73, Drumul Podu Dambovitei, 060652, Bucharest, Romania

2Politehnica University of Bucharest, Faculty of Applied Chemistry and Materials Science, 1-7 Polizu, 011061, Bucharest, Romania

Ifosfamide (IF) degradation from aqueous system via UV-Vis Fe-TiO system was studied for a photo catalyst dose of $200 \mathrm{mg} / \mathrm{L}$ and an irradiation time up to $240 \mathrm{~min}$. IF degradation efficiency was monitored via Liquid Chromatography-Mass Spectrometry technique (LC-MS). Experimental photocatalytic tests were performed both in the absence and presence of 2-propanol and $\mathrm{F}^{-}$radicals' scavengers and the results proved that IF degradation occurs most likely in the bulk solution. Experimental results showed that degradation efficiencies for IF varied between 39.52\% in the presence of 2-propanol and $70.70 \%$ in the scavengers' absence. Six degradation intermediates were identified using the same LC-MS technique and a three stage degradation pathway was proposed based on both available literature data and evolution of degradation intermediates peaks.
\end{abstract}

Keywords: Fe doped $\mathrm{TiO}_{2}$, ifosfamide, heterogeneous photo catalysis, degradation intermediates

Ifosfamide (IF) N,3-bis(2-chloroethyl)-1,3,2-oxazaphosphinan-2-amine 2-oxide is a pharmaceutical active compound widely used in cancer treatment that presents genotoxic, carcinogenic, mutagenic and teratogenic potential even at very low concentrations. On the other hand their metabolites may prove to be more toxic compared with parent compound [1]. The main pollution sources with If are represented by anti-cancer drugs synthesis wastewater and discharges from oncological clinics [2-4]. The total amount of IF and its metabolites eliminated by human body in a $24 \mathrm{~h}$ period represents $50 \%$ of administered IF dose [5] and ends up in the sewerage system [6].

Research studies proved that the exposure to such pollutants and/or their metabolites can led to negative effects on aquatic ecosystems status and therefore to human health [7]. Consequently, present research works are focussed on the implementation of advanced removal technologies of cytostatic drugs from wastewater flows. The most recentreported studies were focussed on hybrid processes applications such as oncological wastewater treatment by membrane bioreactors [8], pharmaceuticals compound removal via a photocatalytic membrane reactor [9]. Among classical oxidants, ozone seems to be the only which allows the advanced degradation of cytostatic drugs (including IF) [10, 11]. Beside these treatment routes, a promising method for treatment of wastewater with pharmaceuticals content is represented by advanced oxidation processes in general both in homogenous (UV/ $\mathrm{H}_{2} \mathrm{O}_{2}, \mathrm{UV} / \mathrm{H}_{2} \mathrm{O}_{2} / \mathrm{Fe}^{2+}$ ) or heterogeneous (UV-Vis/TiO system) [12-21]. Even if there are available data on oxazophosphorine photo-degradation kinetics, recent studies on their oxidative degradation pathways are focussing mainly on cyclophosphamide [12, 22-24] and only few data are available regarding IF degradation pathways [25].

In this context, the elucidation of IF photo-catalytic degradation mechanism may represent a step forward towards implementation of advanced treatment technologies for removal of emerging micro-pollutants such as cytostatic drugs from wastewater.

\section{Experimental part}

Photo catalytic degradation experiments were performed using a Heraeus UV reactor with a TQ-150-Z1 medium pressure mercury lamp (300-500 nm). Samples were bubbled with air (50L/h) in the dark for $30 \mathrm{~min}$ prior to irradiation in order to attain pollutant adsorption equilibrium and delay holes-electrons recombination. All experiments were duplicated in order to assure results' reproducibility.

The following reagents were used for photo catalytic experiments: Ifosfamide (Sigma -Aldrich), 5\%wt.Fe-TiO (provided by Ilie Murgulescu Institute of Physical Chemistry), 2-propanol (J.T. Baker), NaF (Merck).

LC-MS analysis was performed using an Agilent LC-MS system (Agilent, Waldbronn, Germany) consisting of: binary pump, auto-sampler, column compartment and Triple-Quadrupole mass analyzer with electrospray ionization source (ESI). Chromatographic runs were carried out on a Hypersil Gold column (100 x $2.1 \mathrm{~mm}, 3.0 \mu \mathrm{m})$ from Thermo Scientific, which was kept at $25^{\circ} \mathrm{C}$. Starting mobile phase composition was $0.25 \%$ formic acid in $\mathrm{H}_{2} \mathrm{O}$ $(A)$ and $A C N(B)$ in the ratio 90/10. Analytes were separated with a gradient elution program, as follows: $0-1 \mathrm{~min} 10 \% \mathrm{~B}$, $1-4$ min $10-40 \% \mathrm{~B}$, 4-8 min 40\%B, 8-11 min 40-70\%B, 11-12 min 70\%B. A low mobile phase flow of $0.2 \mathrm{~mL} / \mathrm{min}$ was chosen to enhance ESI ionization and method sensitivity. Injection volume of $10 \mu \mathrm{L}$ was used. MS detection of IF and its degradation products was done in positive Full-scan mode in the range $120-300 \mathrm{Da}$ ( $0.1 \mathrm{Da}$ step). ESI ionization source parameters were: $300^{\circ} \mathrm{C}$ drying gas temperature, $10 \mathrm{~L} /$ min drying gas flow-rate, 50 psi nebulizer pressure and $4000 \mathrm{~V}$ capillary voltage.

HPLC grade acetonitrile (ACN) and LC-MS grade formic acid were acquired from Sigma-Aldrich (Germany). Water for chromatography was obtained within the laboratory by means of a MilliQ instrument. These reagents were used for mobile phase preparation.

\section{Results and discussions}

Photocatalytic degradation experiments were performed for an initial IF concentration of about $24 \mathrm{mg} / \mathrm{L}$, a photo catalyst dose $5 \% \mathrm{wt}$. Fe-TiO ${ }_{2}$ of $200 \mathrm{mg} / \mathrm{L}$ and an

\footnotetext{
* email: lucian.constantin@incdecoind.ro
} 
irradiation time up to 240 minutes. The photo catalyst type was selected based on previous research works on oxazophosphorine photo catalysis, which proved that Fe$\mathrm{TiO}_{2}$ photo catalyst was most suitable for cyclophosphamide degradation [25-26].

\section{Effect of the scavengers presence}

In order to verify the possible participation of direct valence holes in the photocatalytic degradation of IF, experiments were performed in the presence of electron donor ( $F^{-}$) due to its ability to adsorb on photo catalyst surface and inhibit generation of hydroxyl radicals $\mathrm{HO} \cdot$ on catalyst surface, therefore enabling the generation of free $\mathrm{HO}$.

Next, IF degradation experiments were performed in the presence of free in bulk solution $\mathrm{HO}$ - scavenger (2-

Table 1

EFFECT OF SCAVENGER PRESENCE ON IF PHOTOCATALYTIC DEGRADATION EFFICIENCIES

\begin{tabular}{|c|c|c|c|c|c|c|}
\hline \multirow{2}{*}{$\begin{array}{l}\text { Irradiation time } \\
\min \end{array}$} & \multicolumn{2}{|c|}{ No scavenger } & \multicolumn{2}{|c|}{$\mathrm{NaF}$} & \multicolumn{2}{|c|}{ 2-Propanol } \\
\hline & $\begin{array}{r}\text { IF] } \\
\mathrm{mg} / \mathrm{L}\end{array}$ & $\begin{array}{l}\eta \\
\%\end{array}$ & $\begin{array}{c}\text { [IF] } \\
\mathrm{mg} / \mathrm{L}\end{array}$ & $\begin{array}{l}\eta \\
\%\end{array}$ & $\begin{array}{c}{[\mathrm{IF}]} \\
\mathrm{mg} / \mathrm{L}\end{array}$ & $\begin{array}{l}\eta \\
\%\end{array}$ \\
\hline 0 & 24.71 & 0.00 & 23.81 & 0.00 & 24.37 & 0.00 \\
\hline 30 & 21.02 & 14.93 & 21.46 & 9.87 & 22.89 & 6.07 \\
\hline 120 & 14.66 & 40.67 & 15.31 & 35.70 & 19.59 & 19.61 \\
\hline 240 & 7.24 & 70.70 & 9.65 & 59.47 & 14.74 & 39.52 \\
\hline
\end{tabular}

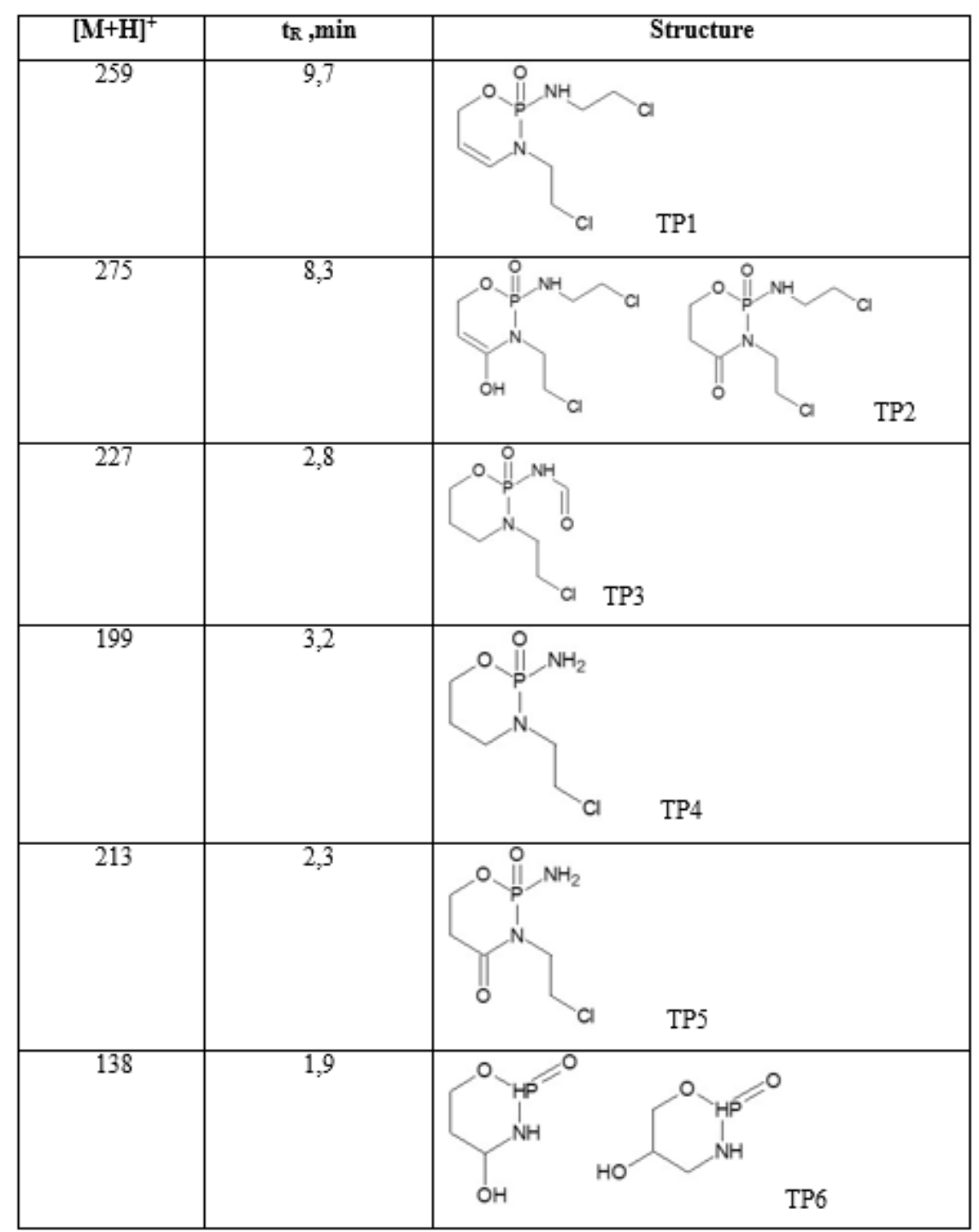

propanol). It should be noted that 2-propanol can act also as electron donor and react with holes. So, when 2-propanol scavenges is used should be considered its capability to react with both hydroxyl radicals and holes.

Scavengers were added in a molar ratio scavenger/IF $=650 / 1$.

The effects of scavengers presence on the IF photocatalytic degradation is graphically presented in the figure 1.

The results confirmed that IF photocatalytic degradation most likely take place in the bulk solution but the reaction of IF with hydroxyl radicals adsorbed on catalyst surface is also possible. This factis similar with other research results reported within the literature for photocatalytic degradation of cyclophosphamide [24, 26-28].

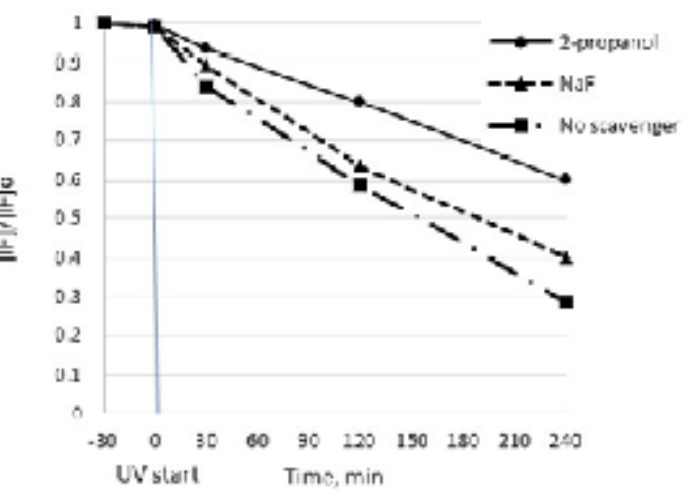

Fig. 1. Variation of normalized IF remanent concentration vs. irradiation time in the scavengers presence

Table 2

IF MAIN DEGRADATION INTERMEDIATES 


\section{Identification of IF degradation intermediates}

In the aim to better understand IF photocatalytic oxidation pathways, degradation intermediates were identified using LC-MS with positive Electrospray ionization (ESI). ESI ionization is known as a soft MS ionization technique generating usually mainly the protonated molecular ion of the analytes $\left([\mathrm{M}+\mathrm{H}]^{+}\right)$which is given by the highest $\mathrm{m} / \mathrm{z}$ signal in the ESI MS spectrum [29, 30]. This allows for an easy identification of the molecular mass of known and especially unknow $n$ degradation products. Starting from the molecular mass of the known compound IF and that of the observed degradation compounds appearing in the MS Scan chromatograms, the latter were identified by taking into account the observed mass difference and also the plausible bond breakage or molecular rearrangement of the IF molecule occurring during the photocatalytic degradation process. The MSscan chromatograms (Scanned MS range: $120 \div 300 \mathrm{Da}$ ) showed the generation of several new peaks that were attributed to six transformation products (TPs) identified as TP1 to TP6. TPs generation was split in three main stages.

During the first stage three TPs were identified. The TP1 was formed by IF dehydrogenation and TP2 2 as generated by IF hydroxylation followed by dehydrogenation. TP3 an aldehyde intermediate of IF was also identified. TP1 and TP2 were also reported within another studies found in the literature but for cyclophosphamide photocatalytic degradation [22, 24, 26] since TP3 an aldo-intermediate of IF was also identified within a previous study on IF degradation [26].

In the second stage, TP4 characterized by $[\mathrm{M}+\mathrm{H}]^{+}=199$ was identified as main intermediate. The final stage is represented by TP4 oxidation to TP5 followed by

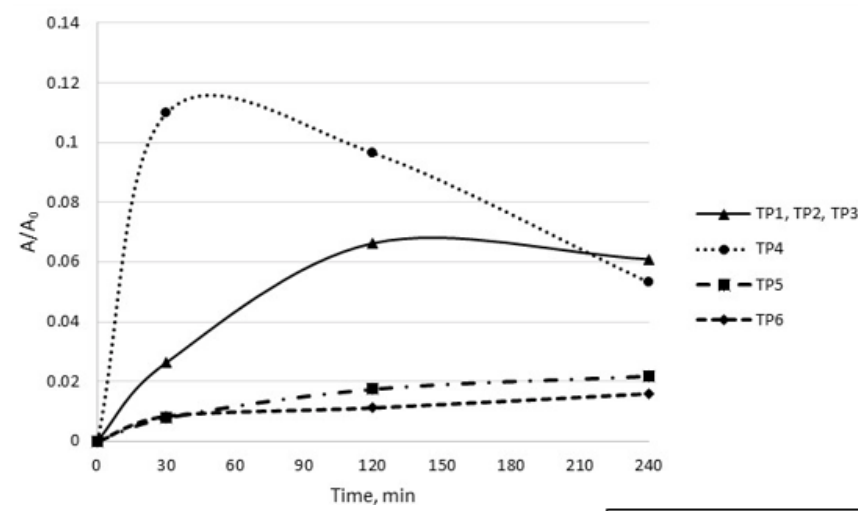

dealkylation to TP6. The same behaviour was reported within the literature but for cyclophosphamide degradation $[22,24]$.

\section{Possible IF degradation pathway}

Based on peak areas presented within chromatographs, the appearance / disappearance of TPs is illustrated within figure 2.

TP1, TP2 and TP3 characterized by $[\mathrm{M}+\mathrm{H}]^{+}=259,275$ and 227 presents the highest signal during the first stage of the process. The signal intensity throughout the entire process decreases in the order: $[\mathrm{M}+\mathrm{H}]^{+}=275>[\mathrm{M}+\mathrm{H}]^{+}$ $=227>[\mathrm{M}+\mathrm{H}]^{+}=259$ proving that TP2 was the main degradation intermediate. The signals presented maximum after 30 min of irradiation and then are permanently decreasing as degradation process advances. If TP3 formation was also reported in previous study on IF photocatalytic degradation [26], the TP1 and TP2 formation was in contradiction with the same mentioned study that founded a compound characterized by $[\mathrm{M}+\mathrm{H}]^{+}=277$ as main intermediate (which was not identified in our study).

As for the second degradation stage, the peak area of TP4 characterized by $[\mathrm{M}+\mathrm{H}]^{+}=199$ increases until 60 minutes of irradiation followed by a decrease at prolonged irradiation time. This resultin accordance with the previous study on IF degradation [26].

Continuous increase of peak areas to IF initial peak area ratios for TP5 and TP6 characterized by $\left[\mathrm{M}+\mathrm{H}^{+}=213\right.$ and $[\mathrm{M}+\mathrm{H}]^{+}=138$ during the whole process proved that those are the degradation intermediates formed in the third stage of the process.

Based on TPs peak areas to initial IF peak area ratios and considering the existing data reported within the literature, a photocatalytic degradation pathway for IF is proposed (scheme 1).

Fig. 2. Appearance / disappearance of TPs peak area $\left(A=T P\right.$ peak area, $A_{0}=I F$ initial peak area)
Scheme 1. Possible IF degradation pathway via UV-Vis/Fe-TiO 2 system

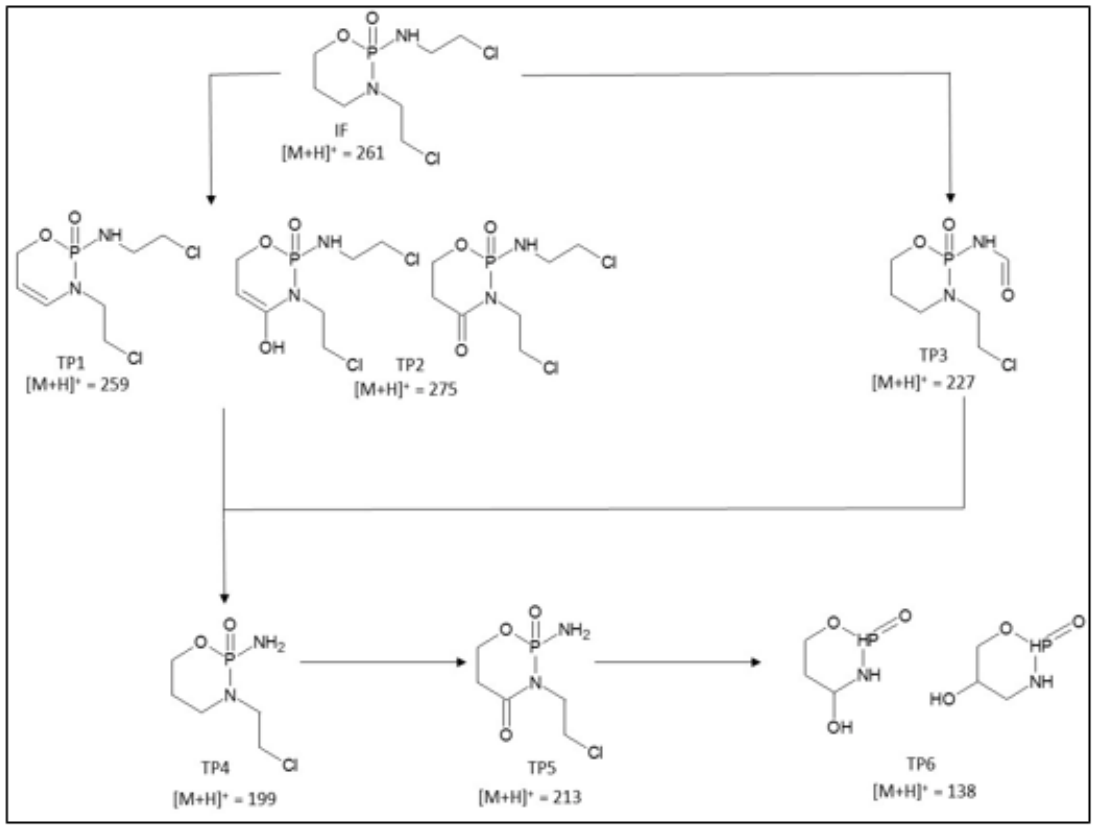

http://www.revistadechimie.ro $\quad$ REV.CHIM.(Bucharest) 69 No. 11 • 2018 


\section{Conclusions}

The photocatalytic oxidation of IF cytostatic drug was studied in the Fe-TiO, /UV-Vis system. The influence of scavengers' presence upon IF degradation efficiency was studied and the results showed that most probably, IF degradation occurs mainly in bulk solution butthe reaction between IF and hydroxyl radicals adsorbed on photo catalyst surface is also possible.

Six degradation intermediates were identified via LCMS technique and a degradation pathway was proposed based on both TPs peak evolution and available data from the literature. The first stage consists in TPs formation directly from IF. In the second stage TPs generated within the first stage are converted to a TP characterized by $[\mathrm{M}+\mathrm{H}]^{+}=199$, and is followed by a third stage in which the latest one is oxidized to a TP characterized by $[\mathrm{M}+\mathrm{H}]^{+}$ $=213$ and further degraded to a TP characterized by $[\mathrm{M}+\mathrm{H}]^{+}=138$.

Acknowledgment: This work was realised through Nucleu Programme with the support of Romanian Ministry of Research and Innovation, Agreement no. 38N/2018, Project PN 180503 01. The authors want to thank to Dr. Maria Crisan from Ilie Murgulescu Institute of Physical Chemistry, Bucharest, Romania for kindly providing the $\mathrm{Fe}-\mathrm{TiO}_{2}$ photo catalyst.

\section{References}

1.NEGREIRA, N., LOPEZ DE ALDA, M., BARCELO, D., Sci. Total Environ., 497-498, 2014, p. 597.

2.CONSTANTIN, L.A., CRISTEA, I., NITOI, I., CONSTANTIN, M.A., NECHIFOR, G., Rev. Chim.(Bucharest), 68, no.8, 2017, p. 1690.

3.REINHOLDS, I., PUGAJ EVA, I., PERKONS, I., LUNDANES, E., RUSKO, J., KIZANE, G., NIKOLAJ EVA, V., MUTERE, O., PETRINA, Z., BAUMANE, L., BARTKEVICS, V., Int. J. Environ. Sci. Technol., 14, no. 9, 2017, p. 1969.

4.GOMEZ-CANELA, C., CAMPOS, B., BARATA, C., LACORTE, S., Int. J. Environ. Sci. Technol., 12, no.2, 2015, p. 633.

5.ZHANG, J., TIAN, Q., ZHOU, S., Curr. Drug Ther., 1, no.1, 2006, p. 55. 6.RUSSO, C., LAVORGNA, M., CESEN, M., KOSJ EK, T., HEATH, E., ISIDORI, M., Environ. Pollut., 233, 2018, p. 356.

7.ZHANG, J., CHANG, V., GIANNIS, A., WANG, J.Y., Sci. Total Environ., 445, 2013, p. 281.

8.HAMON, P., MOULIN, P., ERCOLEI, L., MARROT, B., J. Water Process Eng., 21, 2018, p. 9.

9.J ANSSENS, R., MANDAL, M.K., DUBEY, K.K., LUIS, P., Sci. Total Environ., 599-600, 2017, p. 612.

10.FERRE-ARACIL, J ., VALCARCEL, Y., NEGREIRA, N., LOPEZ DE ALDA, M., BARCELO, D., Sci. Total Environ., 556, 2016, p. 70.
11.VENTA, M.B., CASTRO, C.H., GARCIA, L.A.F., MARZO, A.L., LORENZO, E.V., ALVAREZ, C.A., J. Water Supply Res. T., 54, no. 7, 2005, p. 403.

12.LUTTERBECK, C., MACHADO, E., KUMMERER, K., Chemosphere, 120, 2015, p. 538

13.ADISHKUMAR, S., SIVAJ OTHI, S., BANU, J.R., Desalin. Water Treat., 48, no. 1-3, 2012, p. 89.

14.IOVINO, P., CHIANESE, S., CANZANO, S., PRISCIANDARO, M., MUSMARRA, D., Water Air Soil Poll., 227, no. 6, 2016, article 194.

15.CARABIN, A., DROGUI, P., DIDIER, R., Water Air Soil Poll., 227, no. 4, 2016, article 122.

16.AKHTAR, J., AMIN, N.S., JUNJIE, W., J. Water Supply Res. T., 61, no. 7, 2012, p. 413.

17.CONSTANTIN, L.A., NITOI, I., CRISTEA, I., OANCEA, P., Rev. Chim. (Bucharest), 67, no. 8, 2016, p. 1447.

18.AGGARWAL, K., VERMA, A., BANSAL, P., SINGH, A., Braz. J. Chem. Eng., 34, no. 3, 2017, p. 747.

19.AZIZI, E., FALZADEH, M., GHAYEBZADEH, M., HEMATI, L., BEIKMOHAMMADI, M., GHAFFARI, H.R., ZAKERI, H.R., SHARAFI, K., Enviro. Prot. Eng., 43, no. 1, 2017, p. 183.

20.KAMINSKA, B., SKWIERAWSKA, A., KOZLOWSKA-TYLINGO, K., TOMCZAK-WANDZEL, R., PAZIK, A., MAJ EWSKA, K., Enviro. Prot. Eng., 43, no. 1, 2017, p. 31.

21.NOGUEIRA, K.R.B., TEIXEIRA, A.C.S.C., NASCIMENTO, C.A.O., GUARDANI, R., Braz. J. Chem. Eng., 25, no. 4, 2008, p. 671.

22.LUTTERBECK, C.A., WILDE, M.L., BAGINSKA, E., LEDER, C., MACHADO, E.L., KUMMERER, K., Environ. Pollut. B., 208, 2016, p. 467.

23.ZHANG, Y., XIAO, Y., ZHANG, J., CHANG, V.W.C., LIM, T.-T., J. Environ. Chem. Eng., 5, no. 1, 2017, p. 1133.

24.CONSTANTIN, L.A., GALAON, T., CHIRIAC, F.L., CONSTANTIN, M.A., CRISTEA, N.I., SGEM Vienna Green Sessions, Proceedings, 2017, p. 93.

25.CONSTANTIN, M.A., CONSTANTIN, L.A., CRISTEA, N.I., NITOI, I., 20th International Symposium The Environment \& The Industry, Proceedings, 2017, p. 28.

26.OFIARSKA, A., PIECZYNSKA, A., BORZYSZKOW SKA, A.F., STEPNOW SKI, P., SIEDLECKA, E.M., Chem. Eng. J., 285, 2016, p. 417. 27.RAILEANU, M., CRISAN, M., IANCULESCU, A., CRISAN, D., DRAGAN, N., OSICEANU, P., SOMACESCU, S., STANICA, N., TODAN, L., NITOI, I., Water Air Soil Poll., 224, no. 11, 2013, article 1773.

28.LIN, H.H.-H., LIN, A.Y.-C., Water Res., 48, 2014, p. 559.

29.GALAON, T., VACARASTEANU, C., ANGHEL, D.F., Drug Test. Anal., 6, no. 5, 2014, p. 439.

30. GALAON, T., PETRE, J., IANCU, V.I., CRUCERU., L., NICULESCU, M., CHIRIAC, F.L., PUIU, D.M., MIHALACHE, M., 20th International Symposium The Environment \& The Industry, Proceedings, 2017, p. 229.

Manuscript received: 17.08 .2018 